\title{
Numerical Study on the Stress-Strain Cycle of Thermal Self-Compressing Bonding
}

\author{
Yun-Hua Deng ${ }^{1 *}$, Qiao Guan ${ }^{1,2,3}$, Jun Tao ${ }^{1}$ and Bing Wu ${ }^{3}$
}

\begin{abstract}
Thermal self-compressing bonding (TSCB) is a new solid-state bonding method pioneered by the authors. With electron beam as the non-melted heat source, previous experimental study performed on titanium alloys has proved the feasibility of TSCB. However, the thermal stress-strain process during bonding, which is of very important significance in revealing the mechanism of TSCB, was not analysed. In this paper, finite element analysis method is adopted to numerically study the thermal elasto-plastic stress-strain cycle of thermal self-compressing bonding. It is found that due to the localized heating, a non-uniform temperature distribution is formed during bonding, with the highest temperature existed on the bond interface. The expansion of high temperature materials adjacent to the bond interface are restrained by surrounding cool materials and rigid restraints, and thus an internal elasto-plastic stress-strain field is developed by itself which makes the bond interface subjected to thermal compressive action. This thermal self-compressing action combined with the high temperature on the bond interface promotes the atom diffusion across the bond interface to produce solid-state joints. Due to the relatively large plastic deformation, rigid restraint TSCB obtains sound joints in relatively short time compared to diffusion bonding.
\end{abstract}

Keywords: Thermal self-compressing bonding, Locally non-melted heating, Thermal elasto-plastic stress-strain, Atom diffusion, Solid-state bonding, Finite element analysis

\section{Introduction}

With the rapid development of aviation industry, the requirements of excellent performance, long life and high reliability for both civil and military aircraft become increasingly strict $[1,2]$. To satisfy these requirements, advanced structural materials, such as composite materials, titanium alloys and aluminum alloys, with high specific strength, high specific stiffness and other perfect mechanical and physical properties are developed [3-5]. Meanwhile, welding technique, as an inevitable process for aeronautical manufacturing, also meet the challenge of achieving outstanding welding and joining quality to fulfill the increasingly strict requirements.

Fusion welding process uses the heat source such as arc, laser, and electron beam to heat and melt the

\footnotetext{
${ }^{*}$ Correspondence: yunhuadeng@emails.bjut.edu.cn;

yunhuadeng@buaa.edu.cn

${ }^{1}$ Aeronautical Key Laboratory for Welding and Joining Technologies, AVIC Beijing Aeronautical Manufacturing Technology Research Institute, Beijing 100024, China

Full list of author information is available at the end of the article
}

materials to be joined. Although perpetual joint with acceptable tensile strength can be attained in some cases, fusion welding still has inherent disadvantages. Due to the influence of high temperature thermal cycle by centralized heat source during fusion welding, solidification problems, such as as-cast microstructure and weld defects are always occurred in the weld seams as reported by Kou [6], Li et al. [7] and Chen et al. [8]. This non-homogeneous microstructure combined with weld defects and residual stresses is probably harmful to the mechanical performance of fusion joints, especially to the fatigue property [8-10]. Thus, time-consuming and costly post-weld heat treatment has to be adopted sometimes to improve the comprehensive mechanical properties of fusion joints [11-13].

Compared with fusion welding, solid-state welding method, such as diffusion bonding [14], linear fraction welding [15] and friction stir welding [16], has many outstanding advantages. The first one is solid state joint is attained, which avoid the as-cast microstructure and metallurgical defects such as pores and cracks emerged 
in the fusion joints. Therefore, sound joints with excellent comprehensive mechanical properties are attained. Furthermore, solid-state welding method, especially diffusion welding, can be used to join dissimilar and refractory materials that cannot be welded by fusion welding process $[17,18]$.

In view of the benefits of solid-state welding, a new solid-state bonding method named as rigid restraint thermal self-compressing bonding (TSCB) is pioneered by the authors, which utilizes locally non-melted heating by centralized heat source to produce solid-state joints. Unlike be employed as a fusion heat source during fusion welding, the centralized heat source, such as electron beam (EB), laser beam (LB) or other types of heat source is employed as non-melted one to heat the rigid restrained specimens to be joined as shown in Figure 1 . Under the locally non-melted heating, a thermal compressive effect is expected to be developed and a compressive pressure $F$ will be produced synchronously, which facilitates the atom diffusion between butt-weld specimens to produce permanent solid-state joints [19].

At present, with EB as the non-melted heat source, previous experimental study performed on titanium alloys has proved the feasibility of rigid restraint TSCB [19]. Sound solid-state joints with homogeneous microstructure and good comprehensive mechanical properties were obtained. A comparative study on the microstructure and mechanical properties of the Ti6Al4V joints produced by Electron beam welding and rigid restraint TSCB shown that rigid restraint TSCB joint has better combination of strength and ductility than electron beam welded joint [20]. Meanwhile, rigid restraint TSCB also presented the feasibility of joining dissimilar materials [21]. However, the thermal stress-strain process during bonding, which is of very important significance in revealing the mechanism of TSCB, was not analysed systematically. In this study, finite element analysis method was adopted to numerically study the distributions and developing histories of temperature, stress and strain during rigid restraint TSCB of Ti6Al4V titanium alloys. And then, the bonding mechanism and characteristics of rigid restraint TSCB were investigated.

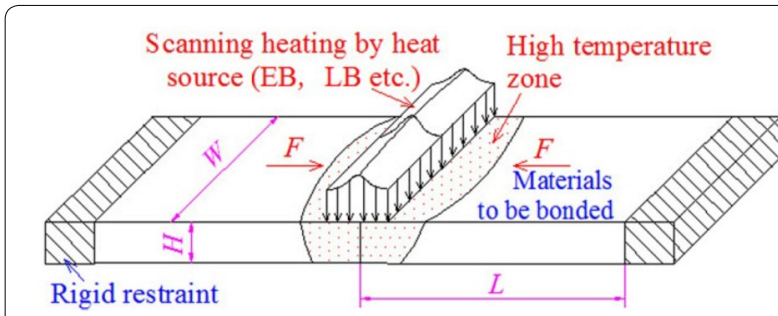

Figure 1 Illustration of rigid restraint TSCB

\section{Numerical Analysis Procedures}

\subsection{Geometry Model and Mesh Generation}

According to previous experimental study, a threedimensional model based on ABAQUS finite element analysis software was built to analyse the thermal stress-strain process during rigid restraint TSCB of Ti6Al4V titanium alloys. Considering the symmetry of the object to be analysed, only half of the joint with the dimensions of $59 \mathrm{~mm}(L) \times 50 \mathrm{~mm}(W) \times 5 \mathrm{~mm}(H)$ was modelled as illustrated in Figure 2. Mesh elements are thickened near the bond interface to attain satisfied computational accuracy, and the smallest element size is $1.0 \mathrm{~mm} \times 1.0 \mathrm{~mm} \times 0.5 \mathrm{~mm}$.

\subsection{Materials Properties}

Temperature-dependent thermophysical properties (conductivity $\lambda$, specific heat $c$ and thermal expansion coefficient $k$ ) and thermomechanical properties (yield strength $\sigma_{\mathrm{y}}$ and elastic module $E$ ) of Ti6Al4V alloy were employed with the values given in Figure 3 [22-24]. Density $\rho$ and Poisson's ratio $v$ of Ti6Al4V alloy were assumed to be independent of temperature with the value of $4420 \mathrm{~kg} / \mathrm{m}^{3}$ and 0.34 , respectively.

\subsection{Thermal Analysis}

Utilizing electron beam as the heat source, previous rigid restraint TSCB experimental was carried out in an electron beam welding machine. A variety of heat source models have been developed to present the keyhole effect and deep penetration phenomenon during electron beam welding such as segmented moving double ellipsoid heat source [25], conical body model [26], rotary Gaussian body model $[27,28]$ and combined heat source model $[29,30]$. However, the electron beam was performed as non-melted heat source during rigid restraint TSCB, therefore Gaussian surface heat source model is more reasonable to reflect the heat transfer of electron beam in current work. Moreover, considering the fast scanning heating of EB as shown in Figure 1, modified Gaussian surface heat source [31] was employed as shown in Figure 4.

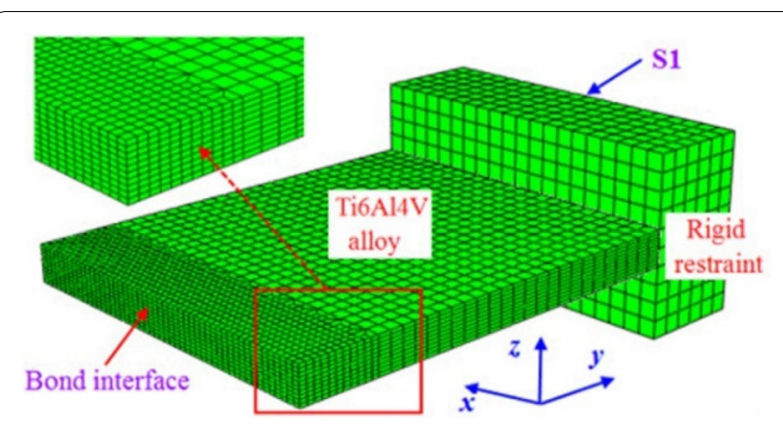

Figure 2 Geometry model and mesh generation 


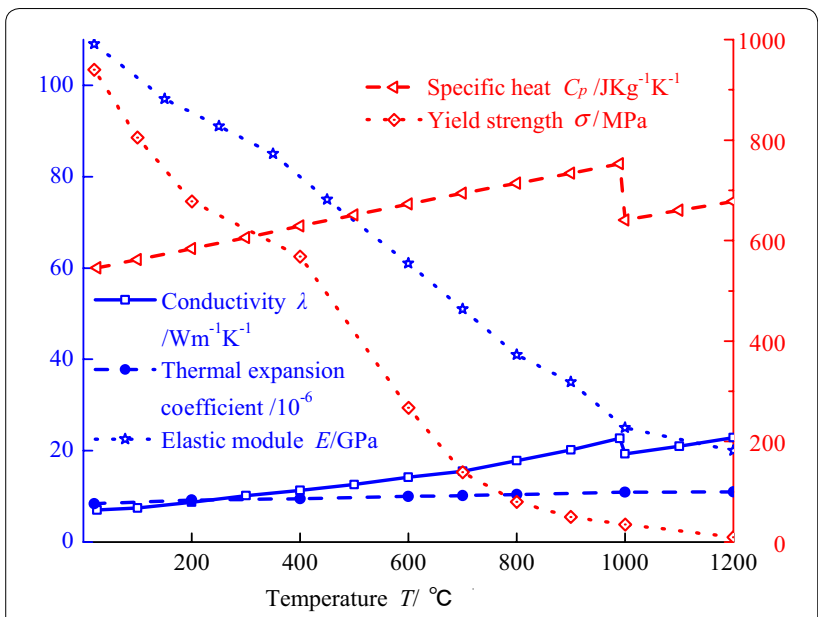

Figure 3 Temperature-dependent materials properties

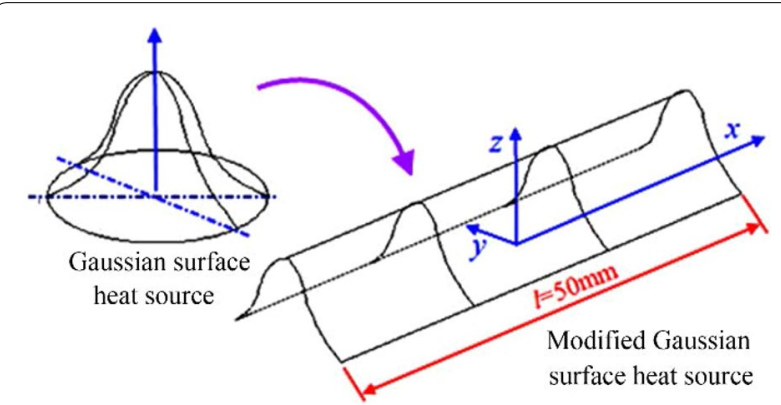

Figure 4 Schematic demonstration of the modified Gaussian surface heat source

The power density distribution can be described as follows [31]:

$$
q=\frac{\sqrt{3} \cdot \eta U_{\mathrm{b}} I_{\mathrm{b}}}{\sqrt{\pi \cdot l R}} \exp \left(-3 \cdot \frac{y^{2}}{R^{2}}\right)
$$

where $q$ is the power density distribution, $\eta$ is the heat efficiency of the power absorbed by the specimen, $U_{\mathrm{b}}$ is the voltage of electron beam heat source, $I_{\mathrm{b}}$ is the current of electron beam heat source, and $l$ is the length of modified Gaussian surface heat source which is equal to the width of the plates to be bonded. $R$ is the effective radius of the heat source. The values of these parameters are presented in Table 1. The heating time of modified Gaussian heat source is $300 \mathrm{~s}$ that is equal to the heating time during rigid restraint TSCB bonding.

Fourier heat conduction equation was used to describe heat propagation. In addition, because the bonding process was carried out in a vacuum, only the heat loss resulting from radiation were taken into account in the model.
Table 1 Parameters employed in the thermal analysis

\begin{tabular}{ll}
\hline Parameter & Value \\
\hline Beam voltage $U_{b}(\mathrm{kV})$ & 150 \\
Beam current $I_{\mathrm{b}}(\mathrm{mA})$ & 1.9 \\
Heating time $t_{\mathrm{H}}(\mathrm{s})$ & 300 \\
Heat efficiency $\eta$ & 0.95 \\
Length of the heat source $/(\mathrm{mm})$ & 50 \\
The effective radius of the heat source $R(\mathrm{~mm})$ & 4
\end{tabular}

\subsection{Mechanical Analysis}

Sequentially coupled thermal and elasto-plastic analyses were employed in present model. Results of calculated temperature field were employed as input conditions for the next mechanical analysis. The material behavior of Ti6Al4V alloy were assumed to be governed by thermal elasto-plastic theory. The von Mises yield criterion and the associated flow rule were adopted in the current work.

Rigid restraint is accomplished through the use of stainless steel plates restrained by a serious of bolts of welding fixture, so the displacement along $y$ direction of the side face $\mathrm{S} 1$ of the restraint was defined as 0 , while with respect to the bond interface the symmetry condition is considered. Other in-plane and out-of-plane displacement boundary conditions are imposed to prevent the rigid movement and rotation of the specimen and rigid restraints as well.

\subsection{Verification of Finite Element Model}

In order to confirm the validity of present model, thermal cycle at the central point of the bonding line on the lower surface and the residual stress distributions on the top surface were measured by thermocouple method and $\mathrm{X}$-ray diffraction method respectively, and the compassion between experimental and numerical results is shown in Figure 5.

It can be seen that slight differences exist in the values between experimental and calculated results. Considering the existence of testing error, it can be suggested that the calculated result is in reasonable agreement with the experimental one. Therefore, present model is reliable to analysis the thermal stress-strain process of rigid restraint TSCB.

\section{Results and Discussion}

\subsection{Thermal Cycle and Temperature Distribution during Rigid Restraint TSCB}

The calculated thermal cycles at different points on the bond interface are illustrated in Figure 6 . It can be seen that under the localized heating of electron beam, temperature on the bond interface is increased during the whole heating period. Meanwhile, the temperature at the central point of the bond line on the top surface, P1, is 


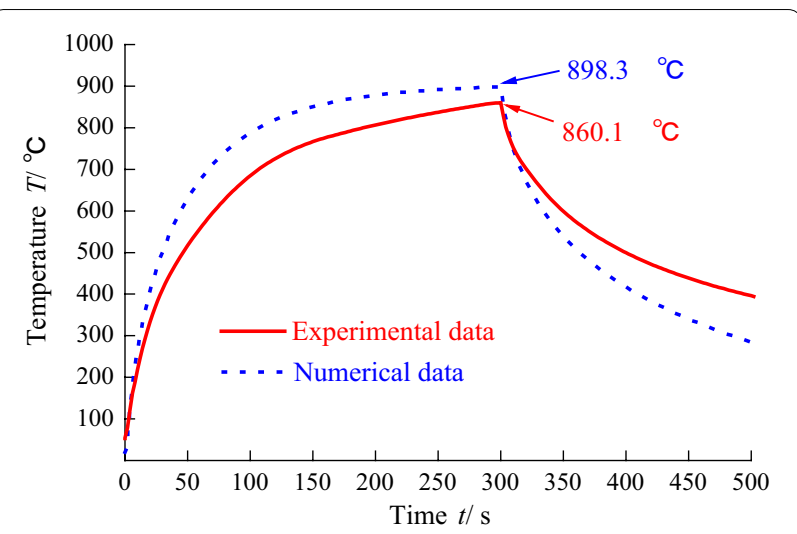

a Thermal cycles during bonding

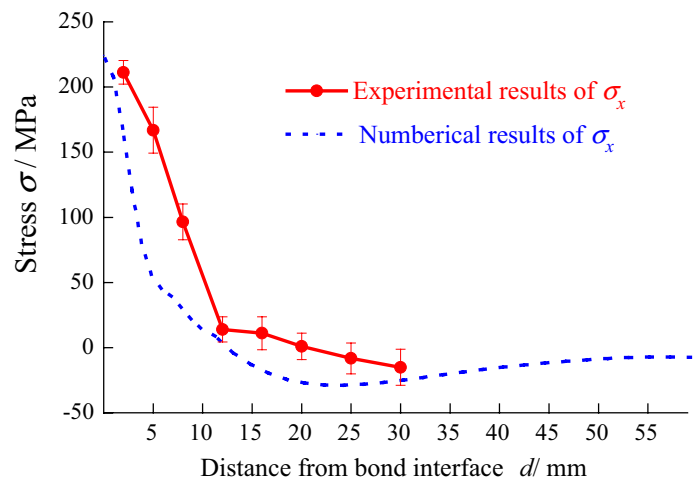

b Residual stress distributions

Figure 5 Comparison between experimental and numerical results

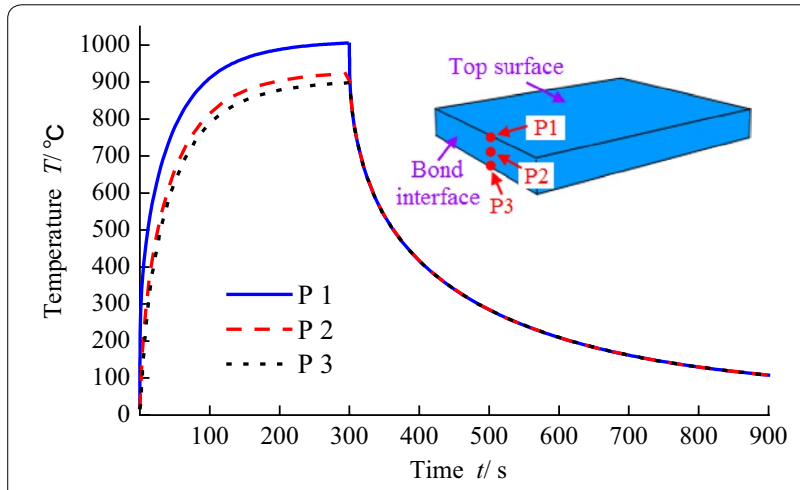

Figure 6 Thermal cycles at different points on the bond interface

slightly larger than that of other points (P2, P3), which is related to that the top surface of the specimen is the heat exchange interface.

At the moment of the end of heating, temperature distribution is shown in Figure 7. Due to the localized scanning heating by electron beam, the temperature distribution along the length of the specimen (the direction perpendicular to the bond interface) is non-uniform. The highest temperature exists in the zone adjacent to bond interface; the farther the distance to the bond interface, the lower the temperature is.

In addition, it can be seen that the peak temperature at the end of heating is approximately $1006{ }^{\circ} \mathrm{C}$ as shown in Figure 7 , which is close to the $\beta$ transus temperature of Ti6Al4V alloy, therefore no significant changes occurred to the microstructure after bonding as shown in Figure 8 and good mechanical properties are obtained as shown in Table 2. By contrast, with respect to electron beam fusion welding, the peak temperature can reach $3000{ }^{\circ} \mathrm{C}$ which
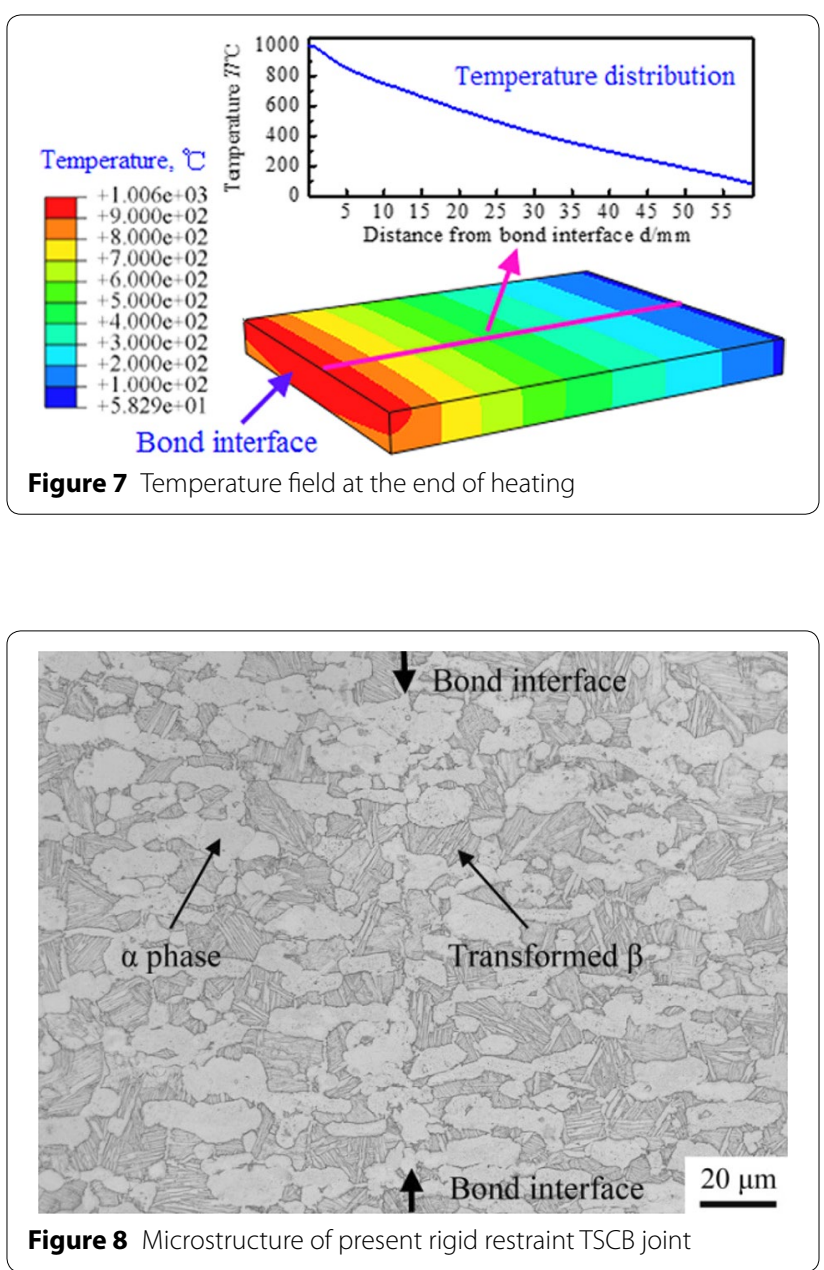

Table 2 Tensile properties of base metal and present joint

\begin{tabular}{lcll}
\hline Type & $\begin{array}{l}\text { Ultimate tensile } \\
\text { strength } \boldsymbol{\sigma}_{\mathbf{b}}(\mathbf{M P a})\end{array}$ & $\begin{array}{l}\text { Elongation } \\
\boldsymbol{\delta}(\%)\end{array}$ & Fractured location \\
\hline Base metal & 999.3 & 17.4 & - \\
TSCB joint & 1037.0 & 16.5 & Base metal \\
\hline
\end{tabular}


is much larger than the melting point of Ti6Al4V alloy; thus solidification problems are occurred in electron beam fusion welded joints.

\subsection{Thermal Stress-strain Evolution during Rigid Restraint TSCB}

The calculated stress and strain histories at the middle point of bond interface are shown in Figure 9. It can be seen that under the heating of electron beam, both longitudinal and transversal compressive stresses are developed at the bond interface because the expansion of high temperature materials close to the bond interface is restrained by surrounding cool materials. Meanwhile, the formation of compressive on the bond interface proves the existence of thermal compressive effect during bonding, and it also suggests that the feasibility of establishing this kind of thermal compressive effect through the locally non-melted heating.
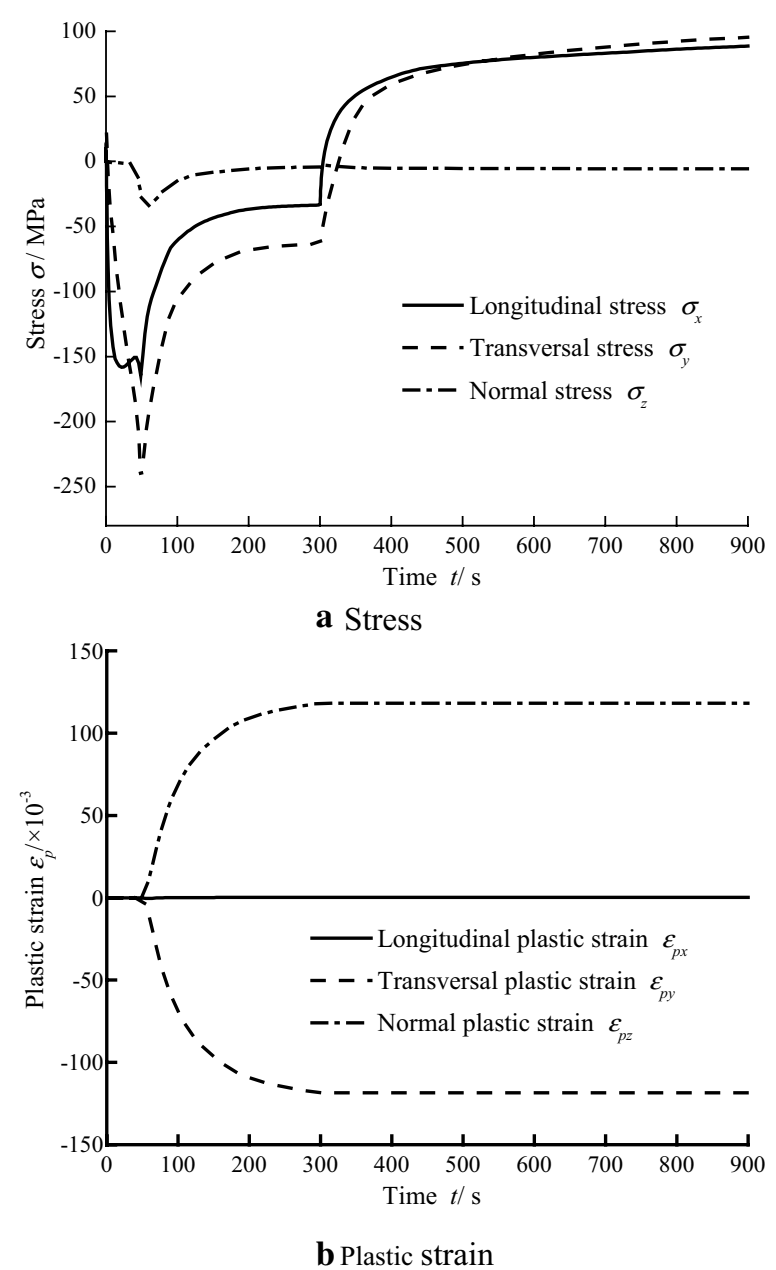

Figure 9 Calculated stress and strain histories at the middle point P2 of the bond interface
In the earlier period during heating process, longitudinal and transversal compressive stresses, $\sigma_{x}$ and $\sigma_{y}$, respectively, are increased quickly by virtue of the fast enhanced thermal compressive effect with the increase of heating time. At the moment of $t=48.7 \mathrm{~s}$, transversal compressive stress is increased to the peak with the value of $-244.3 \mathrm{MPa}$ which is equal to the yield strength of materials at corresponding temperature; and thus plastic deformation is occurred. From this time onwards, compressive stress is decreased gradually with the increase of heating time due to the decreased strength of materials along with the further improvement of temperature. Finally, transversal stress is approximately $-63.2 \mathrm{MPa}$ at the end of heating time. However, the transversal plastic deformation is increased gradually during the whole heating period. During the following cooling process, since the temperature of bond interface decreases more rapidly than that of the region nearby, bond interface is stretched by the surrounding metals. And then the transit compressive stress is transformed to tensile stress. During further cooling process, the longitudinal and transversal tensile stresses on the bond interface increased gradually. With regard to normal stress, the value is very small during the whole bonding process. However, the normal plastic deformation is notable; formed during the whole bonding process and the value of it is almost equal to that of transversal compressive plastic deformation. The whole stress-strain process is under the plane stress state.

Given the transversal compressive action is the majority force to promote atom diffusion between butt-specimens, transversal stress and deformation histories on the entire bond interface during the heating process are investigated as shown in Figure 10. At the moment of $t=55 \mathrm{~s}$, it can be seen that compressive stress is formed on the majority zone of the bond interface because the expansion of elevated metals is subjected to compressive action by the surrounding cool materials and rigid restraints. With the heating time increased to $100 \mathrm{~s}$, compressive stress is developed on the whole bond interface; nerveless, the value of compressive stress is decreased due to the decreased materials strength with further improvement of temperature. However, the plastic deformation is still increased. At the moment of $t=200 \mathrm{~s}$, the value of the compressive stress continues to decrease due to the further increase of temperature. In contrast, the deformation of the bond interface is further increased. At the moment of the end of heating, that is $t=300 \mathrm{~s}$, the value of the compressive stress is slightly decreased due to the limited temperature increase, but the deformation on the bond interface is increased notably due to the limited load bearing capability at elevated temperature. According to above analysis, it can be seen clearly that 


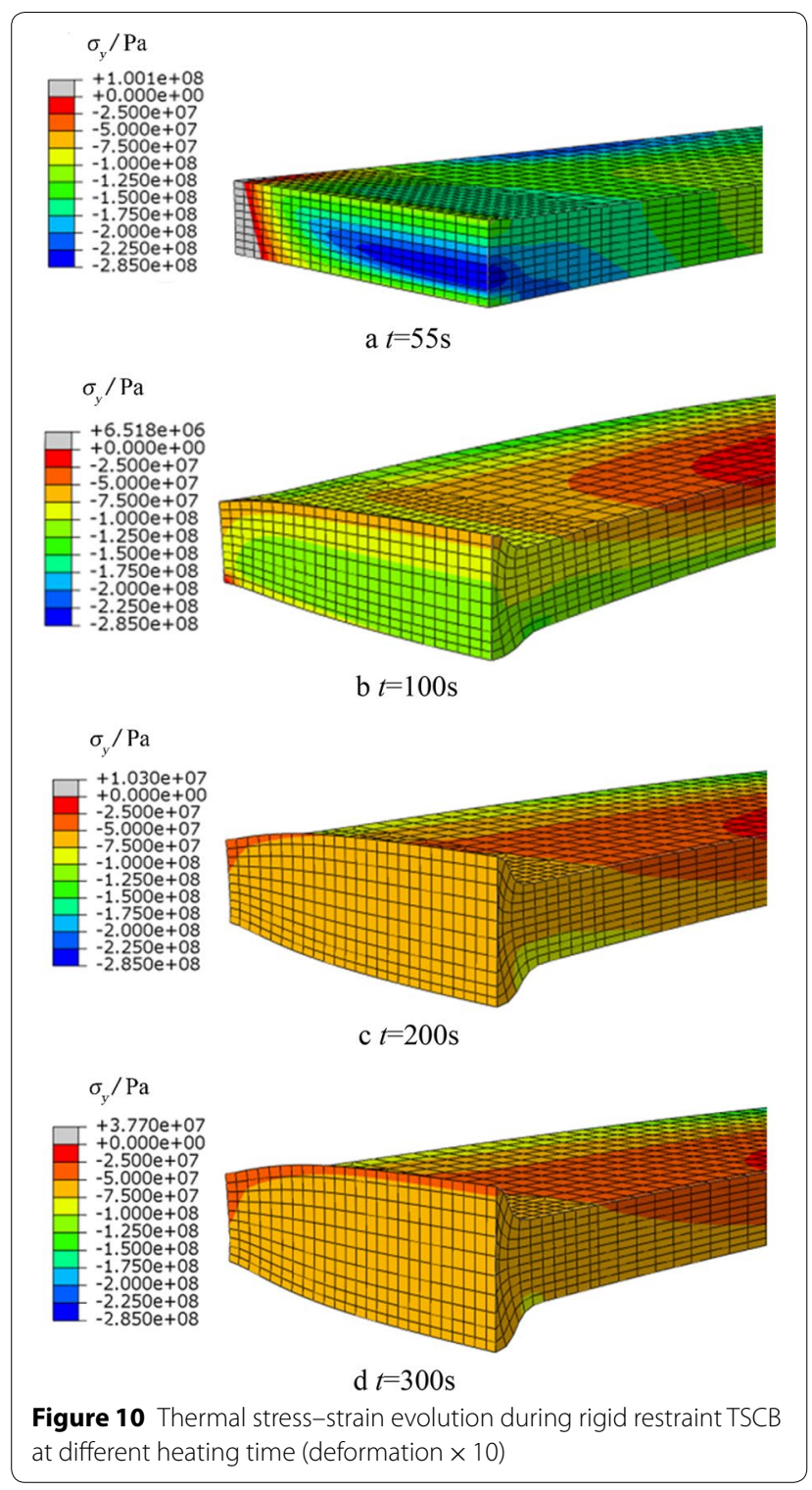

transversal compressive stress and plastic deformation are developed on the entire bond interface during heating period.

\subsection{Bonding Mechanism of Rigid Restraint TSCB}

The heat source in present experimental of rigid restraint TSCB is same to electron beam fusion welding. However, the bonding mechanism of rigid restraint TSCB is notably different from electron beam fusion welding which is dependent on the solidification and crystallization of the welding pool to attain permanent joints while no materials is melted during rigid restraint TSCB. According to above numerical analysis, it can be seen clearly that transversal compressive stress and plastic deformation are developed on the entire bond interface during heating period; meanwhile temperature of materials adjacent to bond interface is high. And thus the requirements of pressure and temperature for atom diffusion are met. Notable atom diffusion between butt-welded specimens is occurred, which promote the formation of permanent solid-state joints. On the other hand, unlike diffusion bonding relied on external force, present method utilizes self-established internal thermal elasto-plastic stressstrain field to promote the atom diffusion between buttspecimens. Therefore it is a thermal self-compressing bonding process.

On the basis of above analysis, it is found that two requirements are needed in order to produce this kind of atom diffusion effect during rigid restraint TSCB. The first one is the internal thermal elasto-plastic stress-strain field established by localized non-melted heating which makes the bond interface subjected to long time compressive action during heating. The other one is that materials at the bond interface should be heated to a high temperature as the atom diffusion coefficient is large at elevated temperature.

In addition, it can be seen that the dwell time over high temperature is short as shown in Figure 6; meanwhile the whole bonding time is only $300 \mathrm{~s}$. Compared to diffusion bonding which also relies on atom diffusion effect, the bonding time of rigid restraint TSCB is relatively short. The main reason may be the relatively large plastic deformation occurred on the bond interface during TSCB process which significantly improves the atom diffusion between materials to be bonded. Therefore, sound solid-state joints can be attaint in a short time by rigid restraint TSCB.

\section{Conclusions}

1. A three-dimensional model based on ABAQUS finite element analysis software was built to analyse the thermal stress-strain process during rigid restraint TSCB of Ti6Al4V titanium alloys.

2. Due to the localized heating, a non-uniform temperature distribution is formed during rigid restraint TSCB, with the highest temperature existed on the bond interface.

3. The high temperature materials adjacent to the bond interface is restrained by surrounding cool materials and rigid restraints, and thus an internal elastoplastic stress-strain field is developed by itself which makes the bond interface subjected to thermal compressive action. This thermal self-compressing action combined with the high temperature on the bond interface promotes the atom diffusion across the bond interface to produce solid-state joints. 
4. In comparison with diffusion bonding, the bonding time of rigid restraint TSCB is short due to the relatively large plastic deformation at the bond interface during rigid restraint TSCB.

\section{Authors' Contributions}

Y-HD and QG were in charge of the whole trial; Y-HD wrote the manuscript; JT and BW assisted with sampling and laboratory analyses. All authors read and approved the final manuscript.

\section{Author details}

${ }^{1}$ Aeronautical Key Laboratory for Welding and Joining Technologies, AVIC Beijing Aeronautical Manufacturing Technology Research Institute, Beijing 100024, China. ${ }^{2}$ School of Mechanical Engineering and Automation, Beihang University, Beijing 100191, China. ${ }^{3}$ Science and Technology on Power Beam Process Laboratory, AVIC Beijing Aeronautical Manufacturing Technology Research Institute, Beijing 100024, China.

\section{Authors' Information}

Yun-Hua Deng, born in 1987, is currently an engineer at Aeronautical Key Laboratory for Welding and Joining Technologies, AVIC Beijing Aeronautical Manufacturing Technology Research Institute, China. He received his $\mathrm{PhD}$ degree on materials processing engineering from Beihang University, China, in 2016. His research interests include solid-state bonding, brazing, electron beam welding and numerical simulation.

Qiao Guan, born in 1935, is currently an academician of the Chinese Academy of Engineering. He received his PhD degree from Bauman Moscow State Technical University, Russia, in 1963. His research interests include aeronautical non-conventional welding/joining techniques, welding mechanics, welding structures and additive manufacturing.

Jun Tao, born in 1977, is currently a senior engineer at Aeronautical Key Laboratory for Welding and Joining Technologies, AVIC Beijing Aeronautical Manufacturing Technology Research Institute, China. He received his PhD degree from Harbin Institute of Technology, China, in 2006. His research interests include fraction welding and numerical simulation.

Bing Wu, born in 1979, is currently a senior engineer at Science and Technology on Power Beam Process Laboratory, AVIC Beijing Aeronautical Manufacturing Technology Research Institute, China. She received her master degree from Tianjin University, China, in 2004. Her research interests include electron beam welding and integrity assessment of welded structures.

\section{Competing Interests}

The authors declare that they have no competing interests.

\section{Funding}

Supported by National Natural Science Foundation of China (Grant No. 51705491).

\section{Publisher's Note}

Springer Nature remains neutral with regard to jurisdictional claims in published maps and institutional affiliations.

Received: 6 November 2016 Accepted: 6 August 2018 Published online: 20 August 2018

\section{References}

[1] G I Nesterenko, B G Nesterenko. Ensuring structural damage tolerance of Russian aircraft. International Journal of Fatigue, 2009, 31 (6): 1054-1061.

[2] R Dilger, H Hickethier, M D Greenhalgh. Eurofighter a safe life aircraft in the age of damage tolerance. International Journal of Fatigue, 2009, 31(6): 1017-1023.

[3] Z Huda, P Edi. Materials selection in design of structures and engines of supersonic aircrafts: A review. Materials \& Design, 2013, 46: 552-560.

[4] J C Williams, E A Starke. Progress in structural materials for aerospace systems. Acta Materialia, 2003, 51(19): 5775-5799.
[5] Z Huda, T Zaharinie, G J Min. Temperature effects on material behavior of aerospace aluminum alloys for subsonic and supersonic aircrafts. Journal of Aerospace Engineering, 2010, 23(2): 124-128.

[6] S Kou. Welding metallurgy. New Jersey: John Wiley \& Sons, 2003

[7] ZX Li, H Wang, Y Li, et al. Progress on effect of processes and microelements on liquation cracking of weld heat-affected zone of nickel-based alloy. Journal of Mechanical Engineering, 2016, 52(6): 37-45. (in Chinese)

[8] X Z Chen, Y C Huang, Z Shen, et al. Effect of thermal cycle on microstructure and mechanical properties of CLAM steel weld CGHAZ. Science and Technology of Welding and Joining, 2013, 18(4): 272-278.

[9] J Liu, X L Gao, L J Zhang, et al. Effects of the heterogeneity in the electron beam welded joint on mechanical properties of Ti6Al4V alloy. Journal of Materials Engineering and Performance, 2014, 20(1): 319-328.

[10] J Ma, Z H Zhao, B H Nie, et al. Research on very high cycle fatigue behavior of the electron beam weldment for TC21 titanium alloy. Journal of Mechanical Engineering, 2015, 51(12): 68-75. (in Chinese)

[11] F Liu, Y H Hwang, SW Nam. The effect of post weld heat treatment on the creep-fatigue behavior of gas tungsten arc welded 308L stainless steel. Materials Science and Engineering A, 2006, 427: 35-41.

[12] G Thomas, V Ramachandra, R Ganeshan. Effect of pre- and post-weld heat treatments on the mechanical properties of electron beam welded Ti-6Al-4V alloy. Journal of Materials Science, 1993, 28(18): 4892-4899.

[13] X Cao, B Rivaux, M Jahazi, et al. Effect of pre- and post-weld heat treatment on metallurgical and tensile properties of Inconel 718 alloy butt joints welded using 4 kW Nd:YAG laser. Journal of Materials Science, 2009, 44(17): 4557-4571.

[14] H J Liu, X L Feng. Study of diffusion bonding of fine grain TC21 titanium alloy. Rare Metal Materials and Engineering, 2009, 38(9): 1509-1513.

[15] S D Meshram, T Mohandas. A comparative evaluation of friction and electron beam welds of near-a titanium alloy. Materials \& Design, 2010, 31 $2245-2252$.

[16] S M O Tavares, J F Santos, P M ST Castro. Friction stir welded joints of Al-Li Alloys for aeronautical applications: butt-joints and tailor welded blanks. Theoretical and Applied Fracture Mechanics, 2013, 65(65): 8-13.

[17] B Kurt, N Orhan, E Evin, et al. Diffusion bonding between Ti-6Al-4V alloy and ferritic stainless steel. Materials Letters, 2007, 61(8-9): 1747-1750.

[18] S J Li, J J Zhang, X B Liang, et al. Joining of carbon fibre reinforced SiC (Cf/ $\mathrm{SiC}$ ) to Ni-based superalloy with multiple interlayers. International Journal of Modern Physics B, 2003, 17 (08n09): 1777-1781.

[19] Y H Deng, Q Guan, B Wu, et al. Study on rigid restraint thermal selfcompressing bonding-A new solid state bonding method. Materials Letters, 2014, 129: 43-45.

[20] Y H Deng, Q Guan, B Wu, et al. A comparative study on electron beam welding and rigid restraint thermal self-compressing bonding for Ti6Al4V alloy. Vacuum, 2015, 117: 17-22

[21] Y H Deng, Q Guan. Rigid restraint thermal self-compressing bonding of pure titanium to titanium alloy. Materials Letters, 2015, 146: 1-3.

[22] KC Mills. Recommended values of thermophysical properties for selected commercial alloys. London: Woodhead Publishing Limited, 2002.

[23] China Aeronautical Materials Handbook Edit Committee. China aeronautical materials handbook. Beijing: China Standard Publishing Company, 2002. (in Chinese)

[24] Y Cai. Research on superplastic tensile mechanical propertities and microstructural evolution of TC4 titanium alloy at high temperature. Nanjing: Nanjing University of Aeronautics and Astronautics, 2009. (in Chinese)

[25] Y Wang, HY Zhao, S Wu, et al. Establishment of segmented moving double ellipsoid heat source model in electron beam welding numerical simulation. Journal of Mechanical Engineering, 2004, 40(2): 165-169. (in Chinese)

[26] P Lacki, K Adamus. Numerical simulation of the electron beam welding process. Computers \& Structures, 2011, 89(1-2): 977-985.

[27] Y Luo, J H Liu, H Ye. An analytical model and tomographic calculation of vacuum electron beam welding heat source. Vacuum, 2010, 84(6): $857-863$

[28] S Rouquette, J Guo, P Le. Estimation of the parameters of a Gaussian heat source by the Levenberg-Marquardt method: Application to the electron beam welding. International Journal of Thermal Sciences, 2007, 46(2): $128-138$

[29] C Liu, B Wu, J X Zhang. Numerical investigation of residual stress in thick titanium alloy plate joined with electron beam welding. Metallurgical and Materials Transactions B, 2010,41(5): 1129-1138. 
[30] P Lacki, K Adamus, P Wieczorek. Theoretical and experimental analysis of thermo-mechanical phenomena during electron beam welding process. Computational Materials Science, 2014, 94: 17-26.
[31] Y W Shi. China materials engineering canon: materials welding engineering. Beijing: Chemical Industry Press, 2006. (in Chinese)
Submit your manuscript to a SpringerOpen ${ }^{\circ}$ journal and benefit from:

- Convenient online submission

- Rigorous peer review

- Open access: articles freely available online

- High visibility within the field

- Retaining the copyright to your article

Submit your next manuscript at $\boldsymbol{\nabla}$ springeropen.com 